\title{
THE POTENTIAL OF VIRTUAL CURRENCIES TO CONTRIBUTE TO THE WELFARE OF INDIVIDUALS AND THE GLOBAL ECONOMIC DEVELOPMENT
}

\author{
Alexandru-Cosmin DUMITRU \\ "Carol I" National Defence University, Bucharest, Romania \\ a.co.dumitru@gmail.com
}

\begin{abstract}
This article focuses on the analysis of the potential of virtual currencies to contribute to global economic development, given their innovative characteristics and their rapid increase in popularity. This article intends to fill the gap in understanding the characteristics and the risks of the emergence of virtual currencies as part of the global financial systems. There is a huge potential of the new currencies backed by blockchain technology, to develop the existing payment systems and upgrade them, as they represent an innovative form of money with increased security of the transactions. For instance, the central banks of some of the world financial leaders, such as the US, UK, China, etc. have been experimenting with the possibility of integrating the technology behind the virtual currencies into the internal payment systems. In this sense, the governments are also working on creating a better legal framework to improve the recognition, licensing and registration of virtual currencies as an official form of payment, and also creating a better control mechanism of the new currency (Vejacka, 2014).
\end{abstract}

KEYWORDS: virtual currencies, disruptive technologies, welfare, economic development

\section{Introduction}

The global financial sector went through an intensive development process in the past century. The economy is under a continuous transformation, updating and adjusting its technological requirements to fit the demands of fiat money and financial relations, as they represent the "blood" of world economies. The main drivers for the fintech innovations have been globalization and digitalization of the global economic systems. Consequently, the regulatory environment is also keeping up the pace and imposes stricter requirements on the payment systems and tools to mitigate the potential risks (Mikhaylov, 2020).
Due to the "crypto hype" created by the social platforms, influential people, and media, it is cumbersome to assess now the importance of this new payment technology and the potential for its development. However, there are signs that virtual currencies may be accepted in the future as means of payment, and potentially to replace fiat money one day. A Government owning virtual currency could have a major advantage in the global financial context and take the lead in the financial arena. Problems such as corruption, money laundering, terrorism financing, dark web purchases, could be potentially solved by the new technology to some extent (Mikhaylov, 2020). 
The objective of this study is to analyse the risks and the advantages of developing virtual currencies as an integral part of the financial system and see how they can positively impact the welfare of individuals. The proposed objectives will be achieved by: studying the theoretical basis of the virtual currencies; providing some considerations on the emergence and development of the virtual currencies and the blockchain technology; analysing the current financial market and making a comparison with the virtual currencies; evaluating the risks and benefits of integrating the virtual currencies to the global financial system.

\section{The Innovation of the Virtual \\ Currencies Market}

At this point, virtual currencies are a novelty for the payment systems and technologies in place, and this completely innovative characteristic is making it unsuitable for the moment for global recognition as a payment instrument. The virtual currency concept is known under many names, the most popular one being "cryptocurrencies" which is derived from the science called cryptography. The objective of this science is to study ways to ensure the confidentiality of information. Since nowadays information is highly correlated to computer sciences, the name of cryptocurrencies is related to the encryption of this type of currency (Tasca, Liu \& Hayes, 2018).

The more general name used for this type of money is 'virtual currency' and it implies the existence of the money under the electronic form, being dependent on networks and computers to function (Mikhaylov, 2020).

\section{Virtual Currencies Lack the Disadvantages of Fiat Money}

By the end of the $20^{\text {th }}$ century, assetbacked currency was replaced by the unsecured paper money, known as fiat money, allowing the states to subordinate the monetary systems and dictate their power, leading to a significant increase of the inflation triggering processes, in this way the resources could be redistributed in the favour of states (Vlasov, 2017). The involvement of the governments in influencing the monetary systems is "parasitic" as through inflation money is redistributed from the ones that produce to the ones that don't. It is essential for a society to intervene forcefully for its survival, and one solution could be the creation of new types of money, that would not allow the state to control inflation. With the information technology revolution which started in the late $20^{\text {th }}$ century, the emergence of a new type of money was possible, under the form of virtual currency - based on the blockchain technology and determined by algorithms, with the advantage that money is not material, so it could not be confiscated by the state, as it happened with gold across the history. In comparison to gold, virtual currencies are intangible and have the advantage that the number of coins, in general, are limited, characteristic that makes inflation impossible. The latter advantage is a significant one in comparison to fiat money and even to gold. Additionally, virtual currencies have the advantage of being extremely secure. Until now, no possible way of breaking the encryption behind them was discovered (Vlasov, 2017).

While some states are attempting to ban virtual currencies, due to the extent of the phenomenon there are not many effective means of fighting it. The appealing characteristics of virtual currencies, when compared to fiat money and commodities, are their immaterial form; their decentralization and the impossibility of state authorities to control the blockchain; inflation policies cannot be carried out due to their limited number. For this reason, it can be said that the emergence of virtual currencies is a 
consequence of technological progress and they truly represent a disruptive technology that can contribute to the development of the monetary systems, the global economy and societies. Nevertheless, the biggest beneficiaries of these new payment technologies will be the states that do not try to fight this phenomenon, but on the contrary, will experiment with incorporating the advantages into their monetary systems. On the other hand, the countries that will be more reluctant and prevent the spread of the phenomenon will be left behind.

\section{The Advantages of Virtual Currencies' Empowerment}

Virtual currencies emerged and initially gained huge popularity in developed economies and are still used most widely in those countries. The question that pops up is whether virtual currencies could be included in a wider context of international development, inclusion in the global financial systems, and bottom-up business efforts. Some of the arguments for the global adoption of the new payment technology include the lowcost remittance for international transfers; decentralized global bank account, without the need to access a commercial bank, accessible simply by using an electronic wallet, rather than having to sign up for a bank account with a financial institution, considering that in some remote areas this is currently impossible; blockchain technology could be used for small-scale international trade and could provide the basis for a more affluent set of financial services (Scott, 2016).

Virtual currencies have the potential to be used by government-backed currencies as intermediaries. Instead of using third parties Money Services Businesses (MSB) (What is the Money Service Business, n.d.) like Western Union, an expat could use a service that converts fiat money to virtual currencies and enables him to transfer the amount to his family, that can withdraw the amount in their local currency.

International payment services are under stress due to many factors. For instance, in underdeveloped countries, there is a threat of shutting down the services due to suspicions of terrorist financing by the banks and states. Payment services are essential for the economy of countries that have large communities living abroad. However, precisely the payment services providers have targeted the banks from the developed countries, in which these communities live. Theoretically, virtual currencies could represent an alternative payments service provided and could facilitate small-scale global commerce. The merchants in underdeveloped countries have limited access, or no access at all, to the international payment systems, making it impossible to sell goods or services abroad. For instance, a manufacturer from an underdeveloped country mightstruggle to integrate card payments on its website, but having a virtual currencies wallet might enable international commerce in exchange for Bitcoin tokens, avoiding the existing eCommerce systems, that can be very costly or even inaccessible due to the fact that a merchant account needs to be set up with a commercial bank. Hence, it could be convenient if markets would allow exchanges of virtual currencies into local fiat money. Individuals are already using virtual currencies for international transfers or to make international payments for the acquisition of goods from different parts of the world from small merchants, but there are no systematic studies of the behaviour of the virtual currencies' users.

The new payments technology could be seen as a type of decentralized bank, as a quasi-bank account for the ones who are struggling with the eCommerce systems, international payments, or with the costs imposed by the financial institutions. With as little as owning a smartphone or a 
personal computer, a virtual currency wallet can be downloaded, and a public key can be easily obtained, which represents the equivalent of a bank account, or a savings account. For the underdeveloped economies, with poor banking infrastructure and high reliance on cash, such a blockchain technology could represent a better and safer alternative to keep money, and also a more convenient option when it comes to regular transactions. Virtual currencies have the potential to complement mobile banking applications, especially in precarious informal settings. The idea that digital wallets are similar to bank account is linked to the idea that individuals could use virtual currencies as replacement for fiat money in countries with unstable economies. On this note, individuals can see virtual currencies as a 'safety boat' to escape their sinking monetary systems. Garrick Hileman (2015) created a Bitcoin Market Potential Index, ranking countries in which the population is most likely to adopt virtual currencies in the future, mainly due to the perceived risk of inflation of their local currency (Hileman, 2015).

\section{Conclusion}

The results of this study lead to the conclusion that newly emerged payment technology offers some considerable advantages over other forms of money (Vlasov, 2017).

The virtual currencies market is under constant development of the technical and technological elements of its system. Every day new virtual currencies are emerging, and the existent ones are being improved or are disappearing. The competition is harsh in the virtual currencies market and only the coins designed for use outside the system can compete with fiat money. Notwithstanding the attractiveness for speculators, or those who engage in illegal transactions, virtual currencies have various features that make them different from fiat money and financial assets. It is important that Governments are experimenting with this technology and try to incorporate the advantages into the international monetary systems, and at the same time mitigate the risks that the use of virtual currencies pose.

\section{REFERENCES}

Hileman, G. (2015). The Bitcoin Market Potential Index. International Conference on Financial Cryptography and Data Security, available at: https://www.researchgate.net/ publication/300472193 The Bitcoin Market Potential Index.

Mikhaylov, Al. (2020). Cryptocurrency Market Analysis from the Open Innovation Perspective. Journal of Open Innovation: Technology, Market, and Complexity, Vol. 6, No. 4, 197. https://doi.org/10.3390/joitmc6040197.

Scott, B. (2016). How can cryptocurrency and blockchain technology play a role in building social and solidarity finance?. UNRISD Working Paper, No. 1, available at: https://www.econstor.eu/bitstream/10419/148750/1/861287290.pdf.

Tasca, P., Liu, S., \& Hayes, A. (2018). The Evolution of the Bitcoin Economy: Extracting and Analyzing the Network of Payment Relationships. Journal of Risk Finance, Vol. 19, Issue 2, 94-126. 
Vejacka, M. (2014). Basic Aspects of Cryptocurrencies. Jurnal of Economy, Business and Finance, Vol. 2, 75-83.

Vlasov, A.V. (2017). The Evolution of E-Money. European Research Studies, Vol. XX, Issue 1, 215-224, available at: https://www.um.edu.mt/library/oar/bitstream/123456789/28785/1/The Evolution_of_E-Money_2017.pdf.

What is the Money Service Business. (n.d.). Available at: https://sanctionscanner.com/ knowledge-base/money-service-business-133. 